\title{
Review Article \\ School Readiness for Young Migrant Children: The Challenge and the Outlook
}

\author{
Smita Mathur' ${ }^{1}$ and Gowri Parameswaran² \\ ${ }^{1}$ University of South Florida, Tampa, FL 33620, USA \\ ${ }^{2}$ New Paltz State University of New York, New Paltz, NY 12561, USA \\ Correspondence should be addressed to Gowri Parameswaran, paramesg@newpaltz.edu
}

Received 8 December 2011; Accepted 29 January 2012

Academic Editor: G. Bagnall

Copyright (C) 2012 S. Mathur and G. Parameswaran. This is an open access article distributed under the Creative Commons Attribution License, which permits unrestricted use, distribution, and reproduction in any medium, provided the original work is properly cited.

\begin{abstract}
There is evidence that children from families of migrant workers are among the most disadvantaged in term of early academic achievement. Yet there are insufficient resources allocated to research exploring the reasons that existing preschool programs are not effective in closing the gap between migrant children and other groups of children in the USA. There are some Head Start programs that migrant children have access to, but many of them offer simply care-giving functions and offer little opportunities for enrichment activities for children in preschool. This paper explores some of the barriers to engaging the preschool child effectively in educational activities.
\end{abstract}

\section{Failing the Migrant Child}

Empirical evidence has uniformly affirmed that young children of migrant farm workers are among the most educationally disadvantaged groups in the United States [1-4]. Over the past decade, researchers have documented multiple factors within the migrant population that are associated with impaired cognitive language, and social development, low levels of academic performance, and an array of adverse educational outcomes [2-11].

Despite the salience of immigration as an ongoing national policy issue, the educational experience of migrant farm worker children has received scant attention. As Margaret Gibson and Livier Bejinez have remarked, the "children of Mexican farm workers are among the most educationally disadvantaged, yet there is little focused research on their school performance patterns or on programs designed to assist them" ([6], page 156). At present, we lack even the most basic information about these underprivileged, underserved, and still largely "invisible" children. There are, for example, glaring disparities in various estimates of their numbers and their school enrollment ([4], page 11, [12], page 26).

The vast majority of migrant farm worker children (roughly 89 percent) are of Mexican descent. Some are first-generation immigrants who were born in Mexico and traveled to the United States with their parents. But preponderance is second-generation immigrants who were born in the United States and are as a consequence American citizens [13]. They confront many of the same educational risk factors that have been found among the children of Hispanic/Latino immigrants at large, including poverty, language barriers, medical and mental health problems, and constraints upon the ability of parents to participate in their development and education both before school age and afterward. The impact of these factors is amplified by household mobility and, in a majority of cases, by restrictions upon their access to publicly funded or subsidized services stemming from the undocumented or "illegal" status of their parents.

As a result of changes in the composition of the American workforce, most children under the age of 6 years old receive some type of nonparental childcare or education prior to school entrance ([14], page 114). While there is a great deal of variance in the provisions of these arrangements, in addition to furnishing basic care "preschools" embody a developmental/educational dimension that is intended to enhance the ability of their students to make the transition to kindergarten classrooms ([15], page 170). Since the 1960s, 
preschool programs have been established for children from disadvantaged backgrounds on the premise that they can improve the school readiness of these prospective students.

\section{Preschools and School Readiness}

With regard to children who are at high risk of school failure, C. T. Ramey and S. L. Ramey's review of the empirical literature led them to conclude that "we now know that we can positively alter the development of young, disadvantaged children through the systematic provision of early childhood education" [16] (page 489). The bulk of the evidence strongly suggests that high-quality preschool programs are generally effective in raising the school readiness of children from low-income households, including members of ethnic/racial minority groups $[14,15,17]$. By virtue of their families' low socioeconomic status, many of the migrant children are eligible to participate in the federal government's Head Start program.

The children of immigrants from Mexico are far less likely to be enrolled in preschools than non-Hispanic whites, African-Americans, and all other major Hispanic ethnic groups, including nonimmigrants of Mexican descent. According to Robert Crosnoe [18], more than two-thirds of children from Mexican immigrant families have no organized educational experience of any type prior to kindergarten enrollment (page 284). Children of migrant farmworkers are eligible to participate in the K-12 MEP, while those under the age of five can enroll in the tuitionfree Migrant and Seasonal Head Start (MSHS) and Migrant Education Even Start (MEES) programs. Akin to Head Start, MSHS and MEES are comprehensive interventions, but their primary mission is to enhance the capacity of migrant children to succeed in the MEP or in non-MEP public school settings. While migrant education, including MSHS, has been in existence since the mid-1960s, "very little is known about how well these programs and services are working" ([3], page 5). There is no national tracking system for MEP, MSHS, or MEES, record-keeping by individual states and by providers is spotty, and given the mobility of migrants, it is exceedingly difficult to conduct the longitudinal research needed to measure program effects. Still from what can be inferred from the literature on Head Start and on preschools that serve Hispanic/Mexican immigrant children, MSHS and MEP should have a significantly positive effect upon the school readiness of migrant farmworker children.

In response to a substantial body of research demonstrating that a large percentage of American youngsters who enter kindergarten are not prepared to learn at the expected level, early childhood researchers have focused their attention on school readiness and the factors than influence it. School readiness is a multidimensional construct. It encompasses cognitive and linguistic development as well as behavioral adaptation to classroom settings. According to Martha Carlton and Adam Winsler [19], current definitions of school readiness have actually merged two distinct concepts: readiness to learn and readiness for school. The former is construed as the level of development at which an individual child is able to learn specific material and is typically assessed in terms of IQ. The latter denotes a child's ability to function successfully within a typical school context. It can be measured through observations of behavior and social interaction or school disciplinary/grade retention data (page 338). An important component of school readiness is empowering the migrant child with cognitive, social, emotional, and physical skills that ensure academic success in elementary school. Additional school readiness implies readiness on part of teachers and early childhood education programs as well as family readiness.

Classroom practitioners possess a substantially different conception of what constitutes "school readiness" from that found in the prescriptive literature. As reported by Currie [20], when kindergarten teachers were asked to identify the primary determinants of school readiness, the most frequently given response was that children who are physically healthy, rested and well nourished were ready for school. This was followed in order by: (1) ability to communicate needs, wants, and thoughts verbally; (2) enthusiasm and curiosity about new activities; (3) willingness to take turns along with knowing how to sit still and pay attention (page 214). Some of these attributes are correlates of intellectual development, but the resultant roster is heavily weighted toward the physical condition, the learning-related attitudes, and the social behaviors of the students. Oddly, only 10 percent of the teachers in this study believed that it was important for children entering kindergarten to know the alphabet (pages 214-215). Plainly operative conceptions of "school readiness" vary substantially as do the instruments that have been used to assess it.

\section{The Ecological Approach to School Readiness}

In Carlton and Winsler's [19] estimation, the traditional definition of school readiness as an achieved level of cognitive development and behavioral maturity "assumes that school readiness is inherent in the child, and that the child must change to fit into existing, homogeneous, and relatively static school programs" ([19], page 338). From this perspective, cognitive development is viewed as precondition for learning that exists independent of content. As an alternative for understanding school readiness, Carlton and Winsler argued for the adoption of Lev Vygtsoky's sociocultural theory of development. In Vygostky's view, development is a process of individualization in which society furnishes the instrumentalities through which individual thinking emerges. Development moves from the outside to the inside.

The essential premise of Vygotsky's theory is that the development of a child's higher-order mental functions does not unfold gradually and autonomously, as Piaget would have it. Development in Vygostky's model is a dialectical process driven by the interaction between cognitive and verbal faculties that have independent roots but that nevertheless intersect at crucial junctures, transforming each other's functions and structures through reciprocal influence.

The most important psychological tools in the Vygostkian learning paradigm consist of the signs and symbols 
that a particular culture has constructed over the course of its history, that is, its linguistic system or code through which it transmits the achievements of past generations down to the child. Hence, as Carlton and Winsler explained, in the socio-cultural model, "the development of higher order human psychological abilities...is a result of the child's history of interacting and participating with others in cultural activities. During the preschool years, as children internalize language and other cultural tools from their collaborative experiences, the cultural line of development reorganizes and transforms the natural biological processes" ([19], page 345). By learning the linguistic code of a particular culture, the child's cognitive development is driven forward. In the sociocultural model, then, learning may spur development, development is inherently social, and it is invariably mediated by culture.

A sociocultural approach to school readiness implies that efforts to facilitate intellectual development must take into account variance in the cultural backgrounds and, above all, the language systems of the cultures to which children are first exposed. In their study advocating bilingual education programs for migrant Mexican students, Gilliard et al. [21] embraced Vygotsky's perspective, asserting that cognitive development is closely linked to language learned within the context of the unique cultural paradigm of a child's family (page 1). They then asked the rhetorical question, "if a child's cognitive schemata for operating in the world are culturally bound, what are the effects of trying to learn in an environment where the culture (and language) of the classroom differs from the culture (and language) of the home?" (page 2) The inference here is that if children are compelled to learn a new linguistic code, English for example, that is not embedded in the culture in which they have been raised; their cognitive development may be impaired. Thus school readiness is not simply a matter of level reached through a child's prior experiences in absorbing specific skills and content. It is, instead, the result of development that occurs through social interaction mediated by elements of culture, notably the child's home language.

The task of analyzing the challenges of and the prospects for improving the school readiness of migrant children is best approached from a broad, ecological perspective. As C. T. Ramey and S. L. Ramey [16] have commented, the factors that influence the school readiness of disadvantaged children cannot be addressed by the schools alone (page 478). The designers of the National School Readiness Indicators Initiative have asserted that the readiness equation encompasses families and communities at large. Similarly, Salinas [4] has formulated an ecological model of migrant children education that depicts overlapping circles of parents, schools, and communities (page 124).

Across the nation, there are some well-established model programs that have been specifically designed to meet the needs of children at high risk of school failure. They provide developmentally appropriate education, often in combination health, nutrition, parenting education, and family support services. "With highly trained teachers and low child-to-staff ratios, they offer quality far superior to most typical early education programs" ([15], page 173).

\section{Some Barriers to the School Readiness of the Migrant Child}

Hispanic educational attainment lags behind whites and African Americans ([22], page 236). Indeed, Hispanics have the lowest rates of college enrollment, the highest rates of high school and college attrition, and the lowest overall educational attainment of all of the major racial and ethnic groups ([23], page 44). As we might anticipate, among all of the larger ethnic groups in the United States, children of Mexican origin are the least likely to graduate from high school, to enroll in college, and to obtain a four-year college degree ([6], page 155). Some major reasons for this lag include the following.

4.1. School Readiness and Socioeconomic Status. According to Crosnoe [18], roughly half of all Mexican immigrant families have household incomes that are below the federal poverty line (page 284). Household poverty exerts a negative influence upon educational performance through multiple pathways. Thus, according to Magnuson et al. [17], families that face severe economic constraints are limited in the quality of the learning experiences that they can furnish to their children.

4.2. School Readiness and Health Status. Poor health and barriers to quality health care exhibit robust correlation with poverty and have a powerful influence upon school readiness. In Currie's [24] estimation, health variables account for about one-quarter of gap in school readiness between white and African-American children. On the whole, Hispanics suffer from poorer physical and mental health than whites, owing to large measure to low levels of health insurance coverage. Clearly, children who suffer from untreated mental health conditions are at elevated risk of school failure. As McCabe et al. [25] have noted, Hispanic children are much less likely to receive mental health services than their white counterparts, despite rates of mental health problems that are as high (or higher) than those found among children in other ethnic groups (page 112). In a study of 372 Mexican families having a child with significant mental health needs, 64 percent of the participants told McCabe et al. that they did not intend to seek treatment for their sons and daughters. While many of those surveyed expressed skepticism about the prospective efficacy of treatment, more than half of the subjects cited difficulties in arranging transportation and child care, while nearly half allowed that they could not afford the cost of treatment (page 116).

4.3. School Readiness and Cultural Beliefs. American teachers who have interacted extensively with the children of Mexican immigrants have remarked that these students tend to be shy and withdrawn, and some scholars have attributed this behavior to cultural values that militate against individual expression ([26], page 53). From their review of the relevant 
literature, McCabe et al. [25] found that in the collectivist Mexican culture the interests of individual family members are subordinate to the well-being of the family as a whole.

4.4. School Readiness and Family Dynamics. There is evidence that domestic violence, spousal abuse, and child abuse are inordinately high within low-income Mexican immigrant families. In their study of low-income Hispanic families, Frias and Angel [27] found that while Dominican and Puerto Rican women report significantly lower rates of domestic violence than African-American women, Mexican-American women are as likely as low-income African-American women to say that they have experienced physical abuse by their spouses (page 561).

4.5. School Involvement. Although Mexican immigrant parents ascribe a much higher value to their children's education than is commonly believed, they are clearly less actively involved in school affairs than mainstream white parents. First-generation Mexican immigrants have low levels of educational attainment, and their own school experience in Mexico does not accord with the intense degree of parental engagement expected of parents by American teachers and school officials. In Reese's [26] study, parents reported that while they tried to meet the expectations and demands of the schools in which their children were enrolled, they experienced a high degree of uncertainty about how this could be done. Language barriers inhibit the participation of Mexican immigrant parents in school affairs.

4.6. School Readiness, Literacy, and Language Skills. Early childhood development studies have highlighted the importance of parents speaking to their children for both language acquisition and cognitive development. By the time they reach the age of two years old, children whose mothers speak to them frequently have vocabularies that are eight times greater than those of children whose mothers speak to them less frequently. Children in rich and highly interactive language environments acquire strong oral language skills, the ability to understand complex spoken language and to express themselves through the use of increasingly specific words in conversational discourse. In addition to oral language, it is during the preschool years that children acquire the rudiments of reading literacy and it is through verbal interaction with parents that they obtain phonological awareness and understanding that printed word corresponds to spoken word in a systematic way. In their investigation of how parenting behavior influences school readiness among white, African-American, and Hispanic children, BrooksGunn and Markman [28] found that minority group parents talk much less frequently to their preschool children than Whites and that they are much less likely to read to them. Similarly, Jiminez et al. [29] reported that Mexican immigrant parents rarely engage in shared reading with their preschool children. Jiminez and her colleagues were able to teach the parents in their study Spanish-language reading strategies, and this, in turn, led to significant increases in the Spanish language literacy of their children. As these investigations suggest, the cognitive/linguistic development and the school readiness of Mexican immigrant children are adversely affected by low levels of parent-child verbal interaction and shared literacy experiences.

A parallel body of research indicates that school efforts to immerse young immigrant children in English language instruction impair their cognitive and linguistic development and their academic achievement. As Collier asserted in 1988, when children under the age of eight are expected to learn a second language before they have mastered the language which they acquired from their parents, "the learning task is very burdensome and requires more time than older children need-children whose first language skills are available for transfer" (page 3). A decade later, Snow et al. [30] wrote that "developing readiness for school is often equated with learning English, despite the evidence that a strong basis in the first language promotes school achievement in the second language (page 157)".

It is also important to acknowledge that there are more than twenty languages spoken in Mexico. These languages are unique and distinct from Spanish. Speakers of these languages may not always fully understand Spanish. Thus, using Spanish as a bridge to learning Standard English is not always a viable option. Additionally, many Mexican farm works are not fluent in written and spoken Spanish making it nonviable to use Spanish to teach standard English. Failure of many attempts to teach English to farm workers is often rooted in this reality

\section{Migrant Head Start Programs}

Established in 1965, Migrant Head Start is a federally funded program operated by the United States Department of Health and Human Services that provides comprehensive preschool education and day care to migrant farm worker children and their families. Since Migrant Head Start (MHS) extends to seasonal workers whose children are participates in interventions of six to eight weeks in duration, it is currently known as Migrant and Seasonal Head Start (MSHS), but the core program furnishes full-day, year-long services. There is, in addition, a Migrant Education Even Start (MEES) program that offers early childhood education, basic adult education, and parental education ([3], page 5). Like the larger Head Start program, eligibility for MSHS and MEES is conditional upon a family income below the federal poverty line. Given pervasive poverty, the vast majority of migrant farm workers with children under the age of six qualify for MSHS or MEES. Based on the Head Start model, MSHS embodies special strategies to address the impediments to school readiness that migrant children face $[8,9,31]$.

The majority of children in Head Start are under 3 years old. Calderon [1] points out, roughly two-thirds of all children in the MSHS in 2001 were under the age of three and essentially receiving daycare without an explicit educational component. In Calderon's estimation, of 161,400 eligible children between the ages of three to five years old, only 31,400 were enrolled in MSHS programs [1]. This figure accords with Salinas's [4] assertion that 33,000 to 34,000 
preschool migrant children (ages three to five) are currently participating in MSHS. These figures strongly suggest that the majority of preschool migrant farm worker children are not currently enrolled in MSHS, with Calderon [1] attributing low levels of participation to inadequate funding.

As with Head Start, MSHS programs receive grant funding from the federal government and are operated by local community organizations. Sessions are geared to the local agricultural schedules, but most are open for nine to ten months of the year ([11], page 3). Some programs are physically housed in specialized migrant worker centers, while others are located within community organization facilities serving low-income, migrant/Hispanic clients.

Although the MSHS is distinct from Head Start itself, preschool services must meet all Head Start Program Performance Standards. They are obligated to provide health screen and preventive health care services as well as lunches/snacks that embody at least one-third of their clients' daily caloric requirements with nutritional foods. MSHS programs are also required to adhere to teacher-child staff ratios and staff certification requirements [1]. It can be reasonably presumed that the quality of the preschool services offered by MSHS programs is roughly comparable to that of Head Start.

Virtually, all MSHS children enter these preschool programs without a working knowledge of English. The program supports the continued development of Spanish language skills along with the acquisition of English ([11], page 3). The overarching goal is to provide children with English and Spanish language skills, but efforts to develop English language proficiency are subordinate to the acquisition of basic Spanish language skills and classes are conducted in Spanish throughout the school year [1]. In the MSHS program, classroom teachers are provided with considerable latitude in alternating between English and Spanish instruction. As one MSHS teacher told Stetchuk and Burns [11]:

\footnotetext{
"We implement a 50/50 approach, which entails a strategy that has teachers focusing on one language one day, and then switching to the other language the next day, and so on. As an example, if the language for Monday is Spanish, then the primary language spoken for the day is Spanish, with availability of an English speaking teacher at all times for those children who do speak English and may choose to communicate in that language" (page 20).
}

While there are substantial variations in manner in which English is integrated into migrant preschools, these programs are designed to build upon basic Spanish language skills that children bring with them from their homes ([11], pages 1-2).

In their study of an MSHS program in Wyoming, Gilliard and her fellow researchers [21] conducted a series of interviews with early childhood educators that affirmed the bilingual and bicultural objectives cited by Stetchuk and Burns. All of the teaching personnel in this program were deeply committed to perpetuating the Spanish language abilities of their students and to conveying the importance of bilingual fluency to their parents. Spanish and English instruction was utilized in every classroom and there was a concerted effort to acknowledge and promote Mexican culture. The participants in Gilliard et al.'s investigation exerted substantial efforts to overcome barriers to parental involvement. Program personnel routinely visited migrant farm worker parents at their temporary homes and communicated with them in Spanish.

Parental involvement is a pillar of the MSHS approach to enhancing the school readiness of migrant children. As in Head Start, MSHS providers are required by law to engage parents and to seek their input on decisions concerning program components and curricula. The complementary Migrant Education Even Start program offers bilingual education to parents and brings parenting instruction classes directly into their homes ([23], page 51).

On the surface then, MSHS/MEES appears to be an effective means of increasing the school readiness of migrant farm worker children. It is comprehensive in its scope, with a particularly strong emphasis upon health and nutrition. It recognizes the importance of building upon the Spanish language skills that preschool migrant children already possess while gradually introducing English language instruction. It seeks to maximize parental engagement in child development and participation in program decisionmaking. In essence, the MSHS embodies the fundamental principles of Head Start while accommodating the particular requirements of Hispanic migrant children's cognitive and linguistic development through bilingual instruction and a bicultural orientation. Given this approach, it is reasonable to believe that MSHS can prove effective as a means for raising the school readiness of migrant children.

\section{Major Constraints on MSHS and Its School Readiness Effects}

Although the approach utilized in MSHS addresses the salient factors that undermine school readiness among migrant farm worker children, there are at least three types of constraints that reduce its effectiveness-program resources, subsequent loss of readiness effects, and punitive public policies directed toward "illegal" immigrants. Relying upon Calderon's [1] estimate that less than twenty percent of all eligible migrant preschoolers between the ages of three to five are enrolled in MSHS, a primary constraint lies in program resource shortfalls. As Takanishi [32] has argued, the greatest problem affecting the early education of immigrant children is a dearth of well-qualified, experienced teachers that are able to deliver bilingual instruction and have an adequate knowledge of Hispanic/Mexican culture (page 73). When Stipek et al. [33] piloted an experimental bilingual program designed for Spanish-speaking youngsters enrolled in kindergarten through the third grade, they found that the protocol was not followed because predominantly English-speaking teachers used much less Spanish language instruction than the researchers had anticipated. 
As Bohon et al. [23] found in their barriers study, even within the MEP that bilingual educators are in short supply. Within a rural mid-west county that relies upon the labor of Mexican migrant farm workers, only two staff members spoke fluent Spanish despite the fact that the vast majority of their students lived in predominantly Spanish-speaking homes (page 51). The sole Hispanic migrant education specialist on the county's staff told the researchers that: "We need many for social workers and teachers who can go to people's houses. And we need people who do not just speak Spanish but also understand Mexican culture" (cited in [23], page 52). She complained that while some teachers were able to communicate in Spanish, they nevertheless lacked sensitivity to Mexican culture. Similarly, in their investigation of an MEP program that required bilingual instruction, Pavri et al. [9] found that teachers were not fluent in Spanish and relied upon in-class translators to assist their students. Although the program was specifically designed to include a balance of English and Spanish language lessons, very little instruction in Spanish occurred owing to a lack of bilingual teaching personnel.

In an evaluation study of two migrant education programs in Ohio, Romanowski [31] found that the primary obstacle to success stemmed from teacher stereotypes about the abilities of migrant students. Even though these programs were directed exclusively to students of Mexican origin, teachers certified as bilingual educators nevertheless possessed very little knowledge of Mexican culture and were reluctant to interact with migrant parents. In Romanowski's view, these MEP staff members exhibited low expectations concerning the learning capacity of their students. None of the staff members in either of these programs had participated in any classes, seminars or conferences addressed to Mexican culture or the particular needs of migrant students.

As noted in passing above, a common complaint about Head Start's effects upon the school readiness of disadvantaged children is that after their entrance into elementary school former participants soon lost the academic and cognitive gains attributed to early intervention. As Zigler and Styfco [34] argued, "this criticism is more appropriately directed toward the elementary schools they attend, for this is where the preschool advantage fades" (page 131). To continue momentum towards school success established in MSHS, "there must be a smooth transition to the school environment and coordinated programming that builds on prior learning." ([2], page 65) Unfortunately, when they enter into mainstream public schools, "migrant students face barriers in school that emerge from the structure of school programs, from their interactions with mainstream classmates, and from their relationships with teachers and other members of the school staff" ([6], page 156). The majority of school districts across the United States are not adequately equipped to meet the academic needs of migrant students ([4], page 26). There are exceptions. Reyes and Fletcher [35] have documented the success of a Texas school district serving migrant farm worker children. They found that a cooperative school culture facilitated academic achievement of these students, with MEP, ESOL and monolingual (English only) teachers engaging in extensive collaboration. On the whole, however, the needs of migrant students have been neglected by public school districts and this, in turn, undermines the positive influence of MSHS.

Citing a study released by the National Association of Bilingual Education in 2000, Green [2] asserted that the United States needs an additional 250,000 certified bilingual teachers to adequately address students who are not English language proficient (page 65). Despite the growing linguistic and cultural heterogeneity of students in American public schools, over 90 percent of all teachers in the United States are of European heritage [21]. Even though research has firmly established that bringing the culture of children's homes into classroom instruction and curriculum can enhance learning experiences, school systems continue to demand that all students quickly embrace school cultures grounded in mainstream norms.

Aside from being poorly prepared to accommodate MSHS students, in at least some communities, migrant children are not welcomed by school personnel ([4], page 30). As might be expected, the children of migrant farm workers are often the victims of racial and class discrimination from their "nonmigrant" peers ([31], page 30). When migrant children enter public schools, the behavior of staff members is frequently seen by the young students to be "derogatory, unaccepting, patronizing, and generally expressive of negative appraisals" ([2], page 64). Perceptions of teacher bias against migrant farm worker students are reinforced by severe shortages in resources dedicated to bilingual and ESOL programs ([23], page 52). As Bohon et al. found in their study of Hispanic immigrant students in Georgia, although staff members exhibited few overt signs of bias against them, students gained the impression that their teachers were disinterested in their performance and simply expected them to fail ([23], page 53).

From her interviews with Mexican immigrant girls attending a mainstream middle school in the rural Southwest, Meador [36] found that her subjects faced stereotypical evaluations from teachers. The students with whom Meador spoke believed that because of their minority, immigrant status, they do not conform to teacher images of a "good student." Moreover, the ESL teachers at the school openly complained that classroom teachers exerted very little effort to establish relationships with Mexican immigrant students (page 152).

There is evidence that the children of migrant farm workers face systematic discrimination by through assignment to programs that separate them from their nonmigrant peers and to schools that are of substandard quality. Razo [37], for example, found that migrant Mexican students were grossly overrepresented in special education programs in the state of Texas. She speculated that their classification as special education students was intended by public school officials to systematically reduce their presence within mainstream classrooms. Valencia (2002) [38] (name on references says: "Valenica 2000") reported that the proportion of migrant Mexican students attending Texas schools was directly associated with the percentage of noncertified teachers on the staffs of the schools. In his estimation, Mexican migrant children confronted a "double disadvantage" comprised of 
the risk factors that they brought with them into Texas public school systems and their disproportionate attendance at poor quality schools.

In a national sample of kindergarten students, Crosnoe [18] reported that young minority group students disproportionately attend schools with a wide variety of problematic characteristics such as high teacher-student ratios, limited teacher experience, and poor school safety records. Compared with White, African American, Asian American, and other Latino kindergarten students, the children of Mexican immigrants were the most likely to be enrolled in schools that were disorganized, resource deprived, displayed an adversarial climate and an impersonal structure, and had low academic focus and constricted curricula. Crosnoe found that kindergarten attendance at problematical schools was strongly correlated with below mean mathematics achievement, mental health/emotional adjustment problems at school and poor interpersonal functioning across all of the $\mathrm{racial} / \mathrm{ethnic}$ groups included in his study's sample. Mexican immigrant students did exhibit some signs of resilience. Their interpersonal functioning was not as heavily influenced by assignment to a problematical school as it was in the case of youngsters from other racial/ethnic backgrounds. Nevertheless, the Mexican immigrant students in the study were clearly "doubly disadvantaged." Under the force of entering kindergarten classes within "problematical schools," the benefits the migrant farm worker children derive from MSHS program participation are plainly vulnerable to rapid erosion.

At the federal, state, and local levels, the basic thrust of public policy toward immigrants over the past two decades has been aimed at deterring illegal immigration through the rescission of social services and the aggressive enforcement of laws against undocumented workers. The principal target of these actions has been Hispanic/Mexican immigrants, including those with dependents who are US citizens. As Salinas [4] has observed, state legislatures within migrant farm worker "base" states (Texas, California, and Florida) have been particularly active in denying basic services to poor undocumented migrant workers and their children (page 134). As early as 1981, the Texas legislature attempted to prohibit undocumented school-age children from access to a free public education. This statute was struck down by the US Supreme Court in Plyler v. Doe [39], but California's Proposition 187 (1994) law nevertheless tried to bar undocumented immigrant children from attending public schools or receiving government-funded medical services ([2], pages 52-55). At the federal level, welfare reform measures passed in the mid-1990s explicitly prohibited immigrants from receiving number of public benefits. These measures undermined the health of migrant children whose parents are no longer eligible to receive food stamps or Medicaid ([40], page 27).

The MEP itself has recently become the target of a federal crackdown on eligibility ([41], page 22). But for preschool immigrant children, the most harmful actions have come in the form of large-scale raids conducted by the US Immigration and Customs Enforcement (ICE) agency. According to Murguia [42], the number of undocumented workers taken into custody by ICE increased forty-five fold between 2001 and 2007 (page 2). There is incontrovertible evidence that ICE agents have monitored facilities housing MSHS programs and that these stake out tactics have exerted a chilling effect upon program participation ([42], page 4). In the aftermath of widely publicized ICE raids in Iowa, migrant parents have withdrawn their preschool children from MSHS and, according to Murguia, during 2007 and 2008 there was a noticeable decline in participation across the United States (page 5). Under these conditions, even those migrant farm worker parents who have entered the country on work visas have become increasingly reluctant to enroll their preschool children in MSHS.

Despite the extremely limited body of published research on the topic, there is no doubt that the school readiness of migrant farm worker children continues to be adversely affected by the full range of risk factors found among the children or poor, Hispanic immigrants in general. Moreover, the transient lifestyle of their families and, in many instances, the undocumented status of their parents, contributes to the disadvantages that young migrant children bring with them to elementary schools. The bulk of the evidence indicates that the school readiness of poor, minority group children can be significantly enhanced through participation in preschool programs, including Head Start. The current Migrant and Seasonal Head Start program embodies features that are associated with effective preschool interventions, and while no independent evaluation studies of MSHS have been conducted, there is good cause to believe that it has assisted children in the transition to formal educational settings. MSHS is comprehensive in the scope of the services that it provides, it explicitly acknowledges the critical importance of parental involvement/engagement, and program providers must meet relatively high standards. MSHS concurrently builds upon the basic language skills that Spanish-speaking migrant children acquire in their homes and gradually introduces English language lessons. In at least some programs, MSHS personnel have attempted to overcome the cultural and linguistic barriers that divide migrant families from mainstream public schools. MSHS can be expected to improve the school readiness of children it serves, furnishing them with a foundation for educational success, and, eventually, upward mobility.

Nevertheless, participation rates in MSHS appear to be inordinately low and in some localities, critical resources shortages are apparent. The cognitive, linguistic, and socioemotional development gains of children who have attended migrant preschools may be reduced or lost altogether after they enter public school systems that are ill equipped to meet their needs. As impoverished members of an ethnic minority that has been subjected to discriminatory treatment, migrant children are likely to attend poorer quality schools or be assigned to programs that separate them from their nonmigrant peers. While the federal government has recognized the importance of furnishing support services to the children of migrant farm workers, current antiimmigrant policies impair their access to programs that are essential to their school readiness. The recent wave of ICE crackdowns is bound to deter many migrant farm workers 
from enrolling their preschool children in MSHS/MEES. Under these conditions, while the means to improve the school readiness of migrant farm worker children has been established, absent broader policy changes, these children will enter kindergarten classes with significant school readiness deficits that are bound to have an enduring impact throughout their school years and into adult.

\section{References}

[1] M. Calderon, Migrant and Seasonal Head Start Action Alert: Help to Increase Funding for Migrant and Seasonal Head Start, 2004.

[2] P. E. Green, "The undocumented: educating the children of migrant workers in America," Bilingual Research Journal, vol. 27, no. 1, pp. 51-71, 2003.

[3] A. L. Kindler, Education of Migrants-Migrant Families, School Programs for Migrant Students, in the Classroom, National and State Programs, 2004.

[4] J.P. Salinas, Educational experiences of children in the migrant stream: ecological factors necessary for academic success, M.Ed. dissertation, Bowling Green State University, 2007.

[5] F. Fuentes and V. D. Cantu, "Migrant head start: what does it mean to involve parents in program services?" Children Today, vol. 24, no. 1, pp. 16-19, 1996.

[6] M. A. Gibson and L. D. Bejinez, "Dropout prevention: how migrant education supports Mexican youth," Journal of Latinos \& Education, vol. 1, no. 3, pp. 155-175, 2002.

[7] M. E. Gwyther and M. Jenkins, "Migrant farm worker children: health status, barriers to care and nursing innovations in health care delivery," Journal of Pediatric Health Care, vol. 12, pp. 60-66, 1997.

[8] R. H. Kozoll, M. D. Osborne, and G. E. Garcia, "Migrant worker children: conceptions of homelessness and implications for education," International Journal of Qualitative Studies in Education, vol. 16, no. 4, pp. 567-585, 2003.

[9] S. Pavri, J. Bentz, J. F. Bradley, and L. Corso, "'Me Amo Leer' reading experiences in a central Illinois summer migrant education programme," Language, Culture and Curriculum, vol. 18, no. 2, pp. 154-163, 2005.

[10] M. Seid and J. W. Varni, "Measuring primary care for children of Latino farmworkers: reliability and validity of the parent's perceptions of primary care measure (P3C)," Maternal and Child Health Journal, vol. 9, no. 1, pp. 49-57, 2005.

[11] R. A. Stetchuk and M. S. Burns, Making a Difference: A Framework for Supporting First and Second Language Development in Preschool Children of Migrant Farm Workers, Academy for Educational Development Center for Early Care and Education, Washington, DC, USA, 2005.

[12] P. A. McHatton, C. P. Zalaquett, and A. Cranson-Gingras, "Achieving success: perceptions of students from Migrant farm worker families," American Secondary Education, vol. 34, no. 2, pp. 25-39, 2006.

[13] Aguirre International, Migrant Education Program Annual Report: Eligibility, Participation, Services 2001-2002 and Achievement (2002-2003), Department of Education, Policy and Programs Study Service, Washington, DC, USA, 2006.

[14] W. S. Barnett and L. N. Masse, "Comparative cost-benefit analysis of the Abecedarian program and its policy implications," Economics of Education Review, vol. 26, no. 1, pp. 113125, 2007.
[15] K. A. Magnuson and J. Waldfogel, "Early childhood care and education: effects on ethnic and racial gaps in school readiness," Future of Children, vol. 15, no. 1, pp. 169-196, 2005.

[16] C. T. Ramey and S. L. Ramey, "Early learning and school readiness: can early intervention make a difference?" MerrillPalmer Quarterly, vol. 50, no. 4, pp. 471-491, 2004.

[17] K. A. Magnuson, M. K. Meyers, C. J. Ruhm, and J. Waldfogel, "Inequality in preschool education and school readiness," American Educational Research Journal, vol. 41, no. 1, pp. 115157, 2004.

[18] R. Crosnoe, "Double disadvantage or signs of resilience? The elementary school contexts of children from Mexican immigrant families," American Educational Research Journal, vol. 42, no. 2, pp. 269-303, 2005.

[19] M. P. Carlton and A. Winsler, "School readiness: the need for a paradigm shift," School Psychology Review, vol. 28, no. 3, pp. 338-352, 1999.

[20] J. Currie, "Early childhood education programs," Journal of Economic Perspectives, vol. 15, no. 2, pp. 213-238, 2001.

[21] J. L. Gilliard, R. A. Moore, and J. J. Lemieux, "'In hispanic culture, the children are the jewels of the family": an investigation of home and community culture in a bilingual early care and education center serving migrant and seasonal farm worker families," Early Childhood Research and Practice, vol. 9, no. 2, 2007.

[22] J. Currie and D. Thomas, "Does Head Start help hispanic children?" Journal of Public Economics, vol. 74, no. 2, pp. 235262, 1999.

[23] S. A. Bohon, H. MacPherson, and J. H. Atiles, "Educational barriers for new Latinos in Georgia," Journal of Latinos and Education, vol. 4, no. 1, pp. 43-58, 2005.

[24] J. Currie, "Health disparities and gaps in school readiness," Future of Children, vol. 15, no. 1, pp. 117-138, 2005.

[25] K. M. McCabe, M. Yeh, A. F. Garland, A. S. Lau, and G. Chavez, "The GANA program: a tailoring approach to adapting parent child interaction therapy for Mexican Americans," Education and Treatment of Children, vol. 28, no. 2, pp. 111-129, 2005.

[26] L. Reese, "Parental strategies in contrasting cultural settings: families in México and "El Norte"," Anthropology and Education Quarterly, vol. 33, no. 1, pp. 30-59, 2002.

[27] S. M. Frias and R. J. Angel, "The risk of partner violence among low-income hispanic subgroups," Journal of Marriage and Family, vol. 67, no. 3, pp. 552-564, 2005.

[28] J. Brooks-Gunn and L. B. Markman, "The contribution of parenting to ethnic and racial gaps in school readiness," Future of Children, vol. 15, no. 1, pp. 139-168, 2005.

[29] T. C. Jiminez, A. L. Filippini, and M. M. Gerber, "Shared reading with Latino families: an analysis of reading instruction and language use," Bilingual Research Journal, vol. 30, no. 2, pp. 431-452, 2006.

[30] C. E. Snow, M. S. Burns, and P. Griffin, Preventing Reading Difficulties in Young Children, National Academy Press, Washington, DC, USA, 1998.

[31] M. H. Romanowski, "Meeting the unique needs of the children of migrant farm workers," Clearing House, vol. 77, no. 1, pp. 27-33, 2003.

[32] R. Takanishi, "Leveling the playing field: supporting immigrant children from birth to eight," Future of Children, vol. 14, no. 2, pp. 61-79, 2004.

[33] D. Stipek, R. Ryan, and R. Alarcón, "Bridging research and practice to develop a two-way bilingual program," Early 
Childhood Research Quarterly, vol. 16, no. 1, pp. 133-149, 2001.

[34] E. Zigler and S. J. Styfco, "Head start: criticisms in a constructive context," American Psychologist, vol. 49, no. 2, pp. 127-132, 1994.

[35] P. Reyes and C. Fletcher, "Successful migrant students: the case of mathematics," Journal of Curriculum and Supervision, vol. 18, no. 4, pp. 306-333, 2003.

[36] E. Meador, "The making of marginality: schooling for Mexican immigrant girls in the rural Southwest," Anthropology and Education Quarterly, vol. 36, no. 2, pp. 149-164, 2005.

[37] N. P. Razo, The representation of migrant students in special education in the State of Texas, M.S. thesis, University of Notre Dame, South Bend, Ind, USA, 2004.

[38] R. R. Valencia, "Mexican Americans don't value education! on the basis of the myth, mythmaking, and debunking," Journal of Latinos and Education, vol. 1, no. 2, pp. 81-103, 2002.

[39] Plyler v. Doe, "Appeal from the united states court of appeals for the fifth circuit," no. 80-1538, 1982.

[40] J. D. Perry, Migrant Education: Thirty Years of Success but Challenges Remain, Department of Education, Washington, DC, USA, 1997.

[41] M. A. Zehr, "Migrant education program draws scrutiny," Education Week, vol. 26, no. 37, pp. 22-33, 2007.

[42] J. Murguia, "The implications of immigration enforcement on America's children," Paper presented to the U.S. House of Representatives Committee on Education and Labor, Subcommittee on Workforce Protections, National Council of La Raza, Washington, DC, USA, May 2008. 

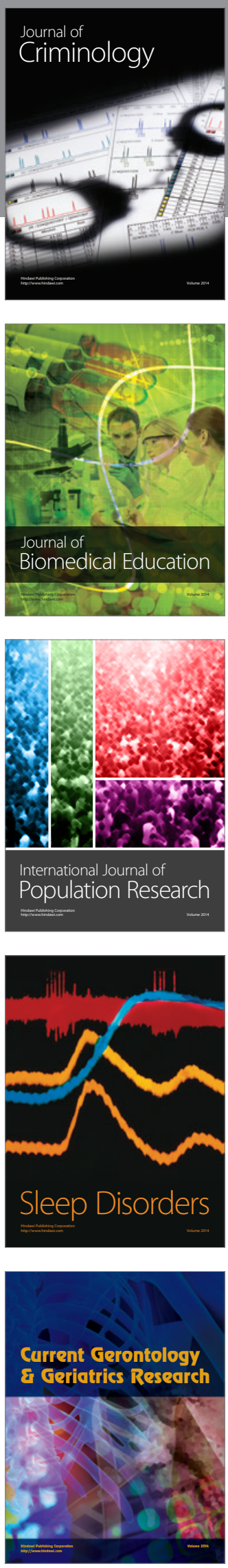
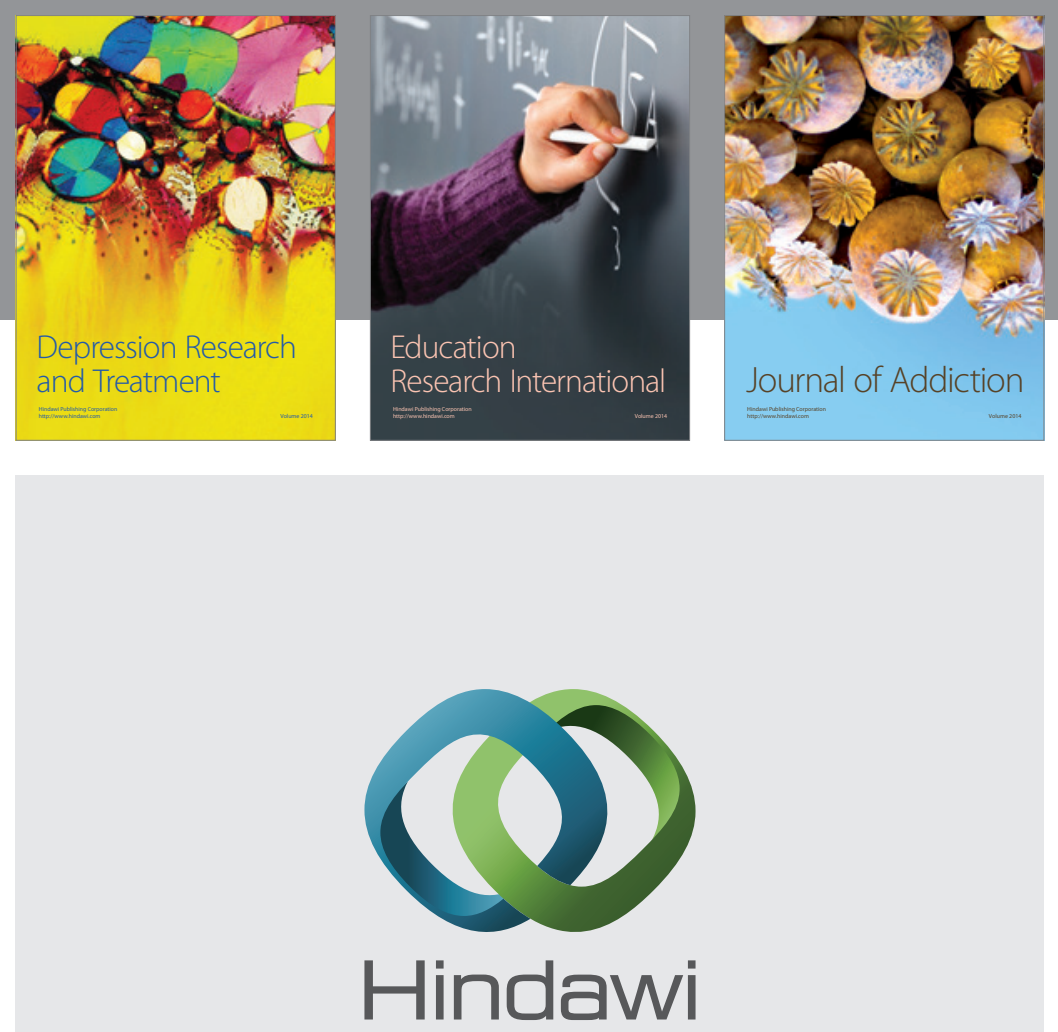

Submit your manuscripts at

http://www.hindawi.com

Child Development Research
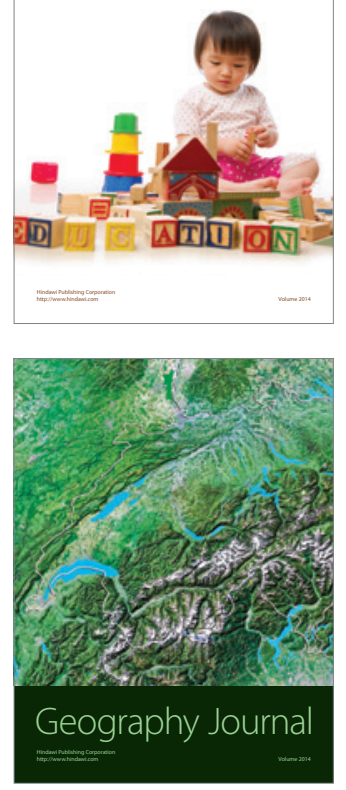

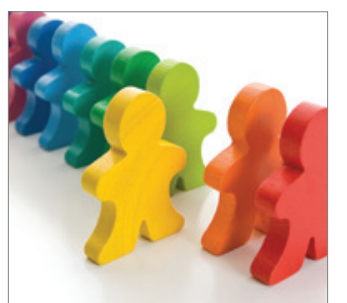

Autism

Research and Treatment
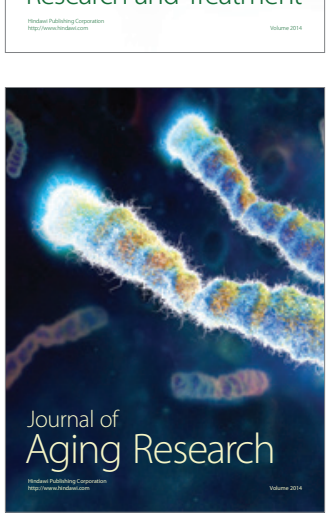
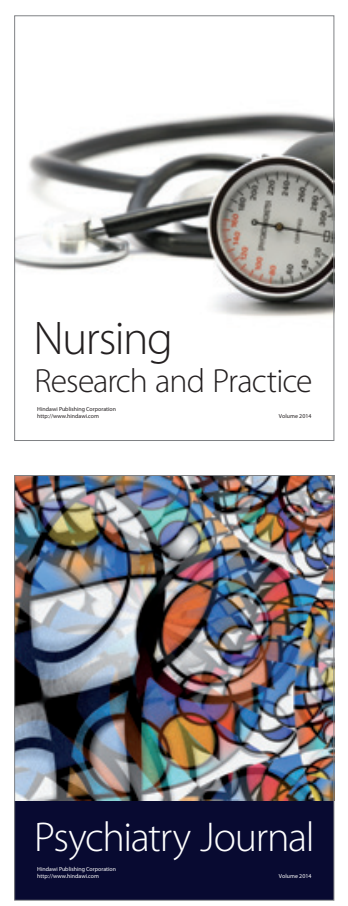
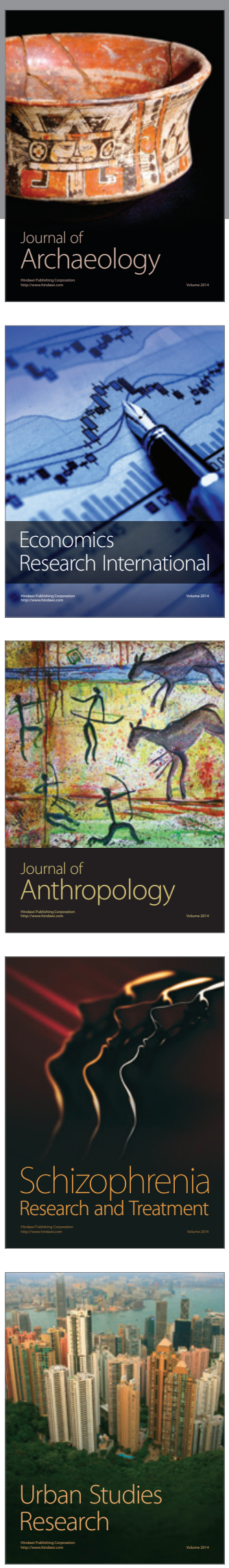